УДК 339.97

\title{
ФОРМИРОВАНИЕ ИННОВАЦИОННЫХ ПРИОРИТЕТОВ РАЗВИТИЯ РОССИЙСКОЙ ФЕДЕРАЦИИ
}

\author{
Приходько Игорь Игоревич \\ аспирант \\ Научный руководитель: Ванюшкин Александр Сергеевич \\ д.т.н., доцент \\ ФГАОУ ВО «Крымский федеральный \\ университет им. В.И. Вернадского»
}

\begin{abstract}
Аннотация: В работе рассмотрены вопросы формирования научнотехнологических приоритетов инновационного развития России. Исследованы основные подходы к формированию научно-технологических приоритетов, структура международного научно-технологического сотрудничества России со странами Европейского Союза, состояние инновационного развития страны. Автором разработан методический инструментарий, благодаря которому скорректированы приоритеты научно-технологического развития России и направления тематик НИОКР с учетом связанности международного научнотехнического сотрудничества РФ и других стран мира, а также межотраслевых мультипликативных эффектов.
\end{abstract}

Ключевые слова: коэффициент связанности научно-технического прогресса, инновации, мультипликатор, драйверы экономики, Арктика, Северный морской путь.

\section{IDENTIFICATION OF INNOVATIVE DEVELOPMENT PRIORITIES OF THE RUSSIAN FEDERATION}

\section{Prikhodko Igor Igorevich}

Scientific supervisor: Alexander Sergeevich Vanyushkin

\begin{abstract}
Paper considers the issues of formation of scientific and technological priorities of innovative development of Russia. The main approaches to the formation of scientific and technological priorities, the structure of international scientific and technological cooperation between Russia and the countries of the European Union, the state of innovative development of the country are investigated.
\end{abstract}


The author has developed methodological tools, thanks to which the priorities of scientific and technological development of Russia and the directions of R\&D topics are adjusted, taking into account the connectivity of international scientific and technical cooperation of the Russian Federation and other countries of the world, as well as intersectoral multiplicative effects.

Key words: the coefficient of connectivity of scientific and technological progress, innovation, multiplier, drivers of the economy, the Arctic, the Northern Sea Route.

Введение. В XXI веке от степени участия страны в международном научно-техническом сотрудничестве и глобальных инновационных процессах в решающей степени зависит успешность поддержания конкурентоспособности национальной экономики. Текущая ситуация, в которой находится Россия, характеризуется, с одной стороны, длительным поиском путей и возможностей диверсификации национальной экономики и отхода от ее сырьевой специализации, а с другой - санкциями, введенными странами Запада и ограничивающими развитие финансовой сферы и стратегически важных отраслей.

За последние 10 лет инновационные приоритеты России закреплялись целым рядом Указов Президента РФ. Несмотря на это, в данном вопросе точка не поставлена до сих пор. Так, наряду с «Перечнем приоритетных направлений развития науки, технологий и техники РФ», впервые закрепленном в Указе Президента РФ № 899 от 07.07.2011 г., и затем измененном в редакции Указа Президента РФ № 623 от 16.12.2015 г., существует также «Перечень критических технологий РФ», утвержденный Указом Президента РФ № 899 от 07.07.2011. К тому же Указом Президента РФ № 642 от 01.12.2016 г. была введена в действие «Стратегия научно-технологического развития РФ», в которой был изменен подход к выделению научно-технологических приоритетов в сторону акцента на поддержке создания конечных продуктов и технологий. Помимо этого, также есть 12 направлений Национальной технологической инициативы (под эгидой АСИ при Президенте РФ) в виде создаваемых рынков профильной инновационной продукции: aero net, mari net, auto net, energy net, tech net, food net, health net, neuro net, safe net, fin net, которые имеют много смысловых пересечений с предыдущими перечнями.

Стоит отметить, что, несмотря на несомненную важность и актуальность, научно-технологические приоритеты, закрепленные во всех вышеперечисленных документах, являются достаточно общими и потому нуждаются в уточнении. 
Это актуализирует поиск приоритетов инновационного развития РФ.

Тематика приоритетов научно-технологического развития РФ рассмотрена в ряде публикаций отечественных авторов: Башкиной Е.М., Едименченко Т.М., Зубарева А.П., Скуратова А.К., Клыпина А.В., Калюжного К.А. и др. В работах перечисленных авторов указывается на изменчивость приоритетов научно-технологического развития РФ, что указывает на непрекращающийся поиск подходов к их выявлению, а также упомянут ряд проблем в этой сфере. В работах Дж. Рифкина[1], П. Марша, К. Андерсона, К. Шваба[2] тематика инновационных приоритетов рассмотрена с позиций глобальных трендов научно-технического прогресса, таких как переход к «гибким» системам производства и их локальному распределению. Также учтена концепция технологических укладов, введенной в научный оборот известным российским ученым, академиком РАН Глазьевым С.Ю.

Целью исследования является выявление приоритетов научнотехнологического развития России в контексте углубления международного научно-технического сотрудничества РФ и других стран мира.

Достижению поставленной цели способствует решение следующих задач:

- изучение возможностей применения основных подходов к выделению приоритетов научно-технологического и инновационного развития РФ;

- анализ тесноты научно-технической кооперации РФ и ЕС в рамках кластеров, технологических платформ, РП ЕС «Горизонт 2020» и ФЦП «ИиР-2020» и выявление наиболее перспективных сфер научно-технического сотрудничества РФ и ЕС;

- выявление приоритетов инновационного развития РФ на основе анализа межотраслевых мультипликаторов.

Научная новизна исследования. Разработан коэффициент связанности научно-технической кооперации, отражающий возможности переориентации на других партнеров в сфере НИОКР и синергетический эффект научнотехнической кооперации.

Научная значимость результатов работы. Совершенствование методического инструментария формирования приоритетов научнотехнологического развития РФ.

Методы и материалы. В процессе исследования использованы методы сравнения, анализа официальной отечественной и зарубежной статистики касательно форм научно-технического сотрудничества, мнений экспертов о межотраслевых эффектах в России, проведены расчеты коэффициента связанности научно-технической кооперации РФ. 
Основной текст. Инновационная политика - это политика государства, заключающая в себе комплекс мер и мероприятий, направленный на обеспечение ускоренного научно-технологического развития страны. Как самостоятельное направление, инновационная политика возникла только во второй половине XX века. Выделение инноваций в качестве отдельного от процесса производства товара и повышение их значимости в обеспечении успешного социально-экономического развития страны заставило многие государства - как развитые, так и развивающиеся - вплотную приступить к регулированию и стимулированию инновационной системы.

Так как целью инновационной политики является в конечном счёте производство инноваций, то и исходить такая политика должна из сущности научно-технологического процесса, его фундаментальных особенностей и тенденций. Формирование научно-технических приоритетов инновационного развития РФ требует пристального изучения проблематики расширения международных научно-технических связей нашей страны, поскольку в современных реалиях ни одна страна мира не может самостоятельно, в отрыве от остальных стран, развивать научные направления в рамках указанных укладов. Следовательно, от тесноты научных связей в решающей мере зависит срок достижения требуемых результатов (разработка новых продуктов, инноваций).

В целях анализа тесноты и возможных перспектив интенсификации международной кооперации России с основными странами-партнёрами при создании инновационных проектов рассмотрим направления и масштабы их взаимного сотрудничества в данной сфере. Для оценки тесноты научнотехнической кооперации, по аналогии с коэффициентом связности в торговле, нами предложен коэффициент связанности научно-технической кооперации.

Связанность научно-технической кооперации между странами отражает коэффициент связанности, рассчитываемый следующим образом:

$$
k_{\text {HTII }}=\frac{X_{m n}}{X_{m}} / \frac{Y_{n m}}{Y_{n}} ;
$$

где $X_{m n}$ - число инновационных кластеров, научно-технологических платформ, соглашений о реализации совместных проектов или программ, задействованных в международной кооперации двух стран в стране $\boldsymbol{m}$; 
$X_{m}$ - общее число научно-технологических платформ, соглашений о реализации совместных проектов или программ в стране $m$;

$Y_{n m}$ - число научно-технологических платформ, соглашений о реализации совместных проектов или программ, задействованных в международной кооперации двух стран в стране $\boldsymbol{n}$;

$Y_{n} \quad$ общее число объектов инновационной инфраструктуры данного типа в стране $n$;

$m, n$ - страны (интеграционные объединения).

Если К Кнтп близок к 1, то научно-техническое сотрудничество между странами можно назвать связанным.

Смысл данного коэффициента следующий: чем больше связанность инновационного развития между странами, тем труднее им переориентироваться на других партнеров в сфере НИОКР и тем большую роль играет синергетический эффект научно-технической кооперации.

Рассчитаем данный коэффициент для нескольких направлений сотрудничества по линии Россия-ЕС. Для начала проанализируем сотрудничество России и Евросоюза при создании инновационных кластеров. Наиболее развитыми направлениями сотрудничества являются Авиационные и космические технологии, а также Микро-, нано- и оптические технологии. Аутсайдерами являются инновационные кластеры по направлениям «Производство и машиностроение» и «ИКТ и креативная индустрия».

По итогам расчётов Коэффициент связанности научно-технического прогресса в области инновационных кластеров оказался равен (страна $m$ - Россия, страна $n$ - Европейский Союз):

$$
k_{\text {НТП }}^{\text {иннокастеры }}=\frac{11}{29} / \frac{32}{834}=\frac{0,379}{0,038}=9,97
$$

Коэффициент свидетельствует о большей диверсификации направлений сотрудничества у Европейского союза и большей зависимости России от научно-технического сотрудничества с ЕС.

Расчёт данных коэффициентов по отраслям дал следующие результаты (см. рис. 1). 


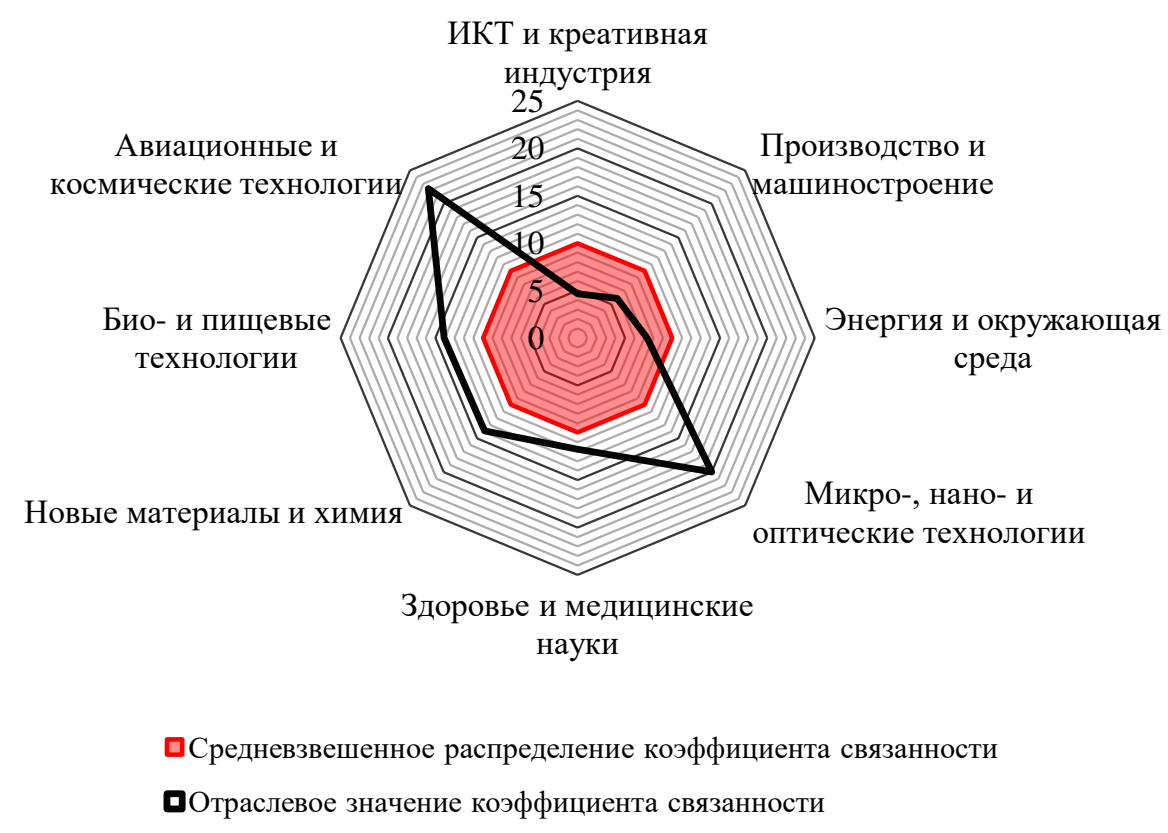

Рис. 1. Паттерн-анализ связанности направлений
научно-технического прогресса по линии Россия-ЕС

в сфере международного взаимодействия инновационных кластеров.

Источник: составлено автором по результатам собственных расчётов.

Анализируя диаграмму, можно сделать вывод о аэрокосмической отрасли как о преимущественно более перспективной для Евросоюза в плане расширения международной научно-технологической кооперации.

В разрезе одной из наиболее перспективных отраслей - микро-, нано- и оптические технологии прослеживаются серьёзные диспропорции в количестве задействованных по данным направлениям инновационных кластеров. Если у России их 4, то в странах ЕС - 122. Не для всех из более, чем сотни кластеров данное направление является центровым, но тем не менее, чётко прослеживается разность в приоритетах научно-технологического сотрудничества. Очевидно, что эта область - одна из наиболее перспективных к сотрудничеству для России.

Высокий уровень развития ядерной энергетики в России обеспечил возможности для широкого научно-технического сотрудничества. Так, среди партнёров ядерно-инновационного кластера города Димитровграда Ульяновской области числится 9 иностранных компаний, из них 8 - из Европейского Союза. С другой стороны, кластеры, нацеленные на охрану окружающей среды менее развиты в России, этим обусловлена величина рассчитанного коэффициента. Так, Евросоюзу выгоднее расширять 
сотрудничество с ядерными кластерами России, а нам - с кластерами ЕС по развитию экологически чистых производств.

Теперь рассчитаем степень тесноты кооперации при заключении Соглашений о реализации совместных программ. Таких программ в рамках сотрудничества Россия-ЕС наличествовало две - это ЭРА HЕТ+ и РП ЕС «Горизонт 2020». Со стороны России была открыта программа «Исследования и разработки по приоритетным направлениям развития научнотехнологического комплекса России на 2014-2020 гг.».

Наша страна в рамках ФЦП ИиР-2020 выделила на сотрудничество с ЕС 4.700 млрд руб., Европейский Союз в рамках программы ЭРА НЕТ+ 14 млн. евро и 70 млн. евро по программе «Горизонт 2020». Всего же на ФЦП ИиР-2020 было выделено 179,8 трлн. руб., а по программе «Горизонт-2020» - 80 млрд. евро.

Рассчитаем коэффициент связанности в рамках РП ЕС «Горизонт 2020»:

$$
k_{\mathrm{HT \Pi}}^{2020}=\frac{4,7}{179,8} / \frac{84}{80000}=\frac{0,026}{0,001}=26,00
$$

Как видим, наша страна находится в достаточно высокой зависимости от научно-технического взаимодействия со странами ЕС. Отсюда, в целях реализации научно-технологического перехода необходимо расширять взаимодействие с европейской наукой, расширять степень включения России в работу рамочных программ ЕС.

Исследование тесноты научно-технологической кооперации необходимо дополнить анализом тех мультипликационных эффектов, которые будут реализовываться в экономике благодаря осуществлению проектов, разработанных в рамках сотрудничества Россия-ЕС, а также с иными странами. Согласно данному подходу, к приоритетным отраслям относятся: станкостроение, приборостроение, авиационная и космическая отрасль, сборка крупнотоннажных судов и т.П. Применение данного подхода способно вывести применяющую его страну на вершины глобальных цепочек добавленной стоимости.

Например, развитие Арктики требует расширения производства в строительстве, нефтегазовой отрасли, судостроении, отсюда - в машиностроении, науке, образовании и пр. Как справедливо отметил министр природы России и экс-губернатор ЯНАО: «Одно рабочее место в Арктике создает 14 рабочих мест в России. В обустройстве Арктики уже сегодня, так 
или иначе, задействованы предприятия 57 регионов. Арктика - это мощный драйвер экономики всей страны» [3].

Нами были проанализированы мнения экспертов $[4,5,6,3,7,8,9,10]$, которые отмечали большую величину данного мультипликативного эффекта. На основе полученных данных была построена диаграмма связанности ключевых отраслей российской экономики (см. рис. 2), из которых мы выделили четыре узловых отрасли - машиностроение, автомобильная, ракетнокосмическая промышленность и развитие Арктики. Именно эти отрасли обладают наибольшим мультипликативным эффектом так как, развиваясь, вовлекают как можно большее число смежных производств, формируют спрос на высокотехнологичную продукцию, требуют постоянного совершенствования науки и техники, нацелены на решение нетривиальных задач инновационного развития.

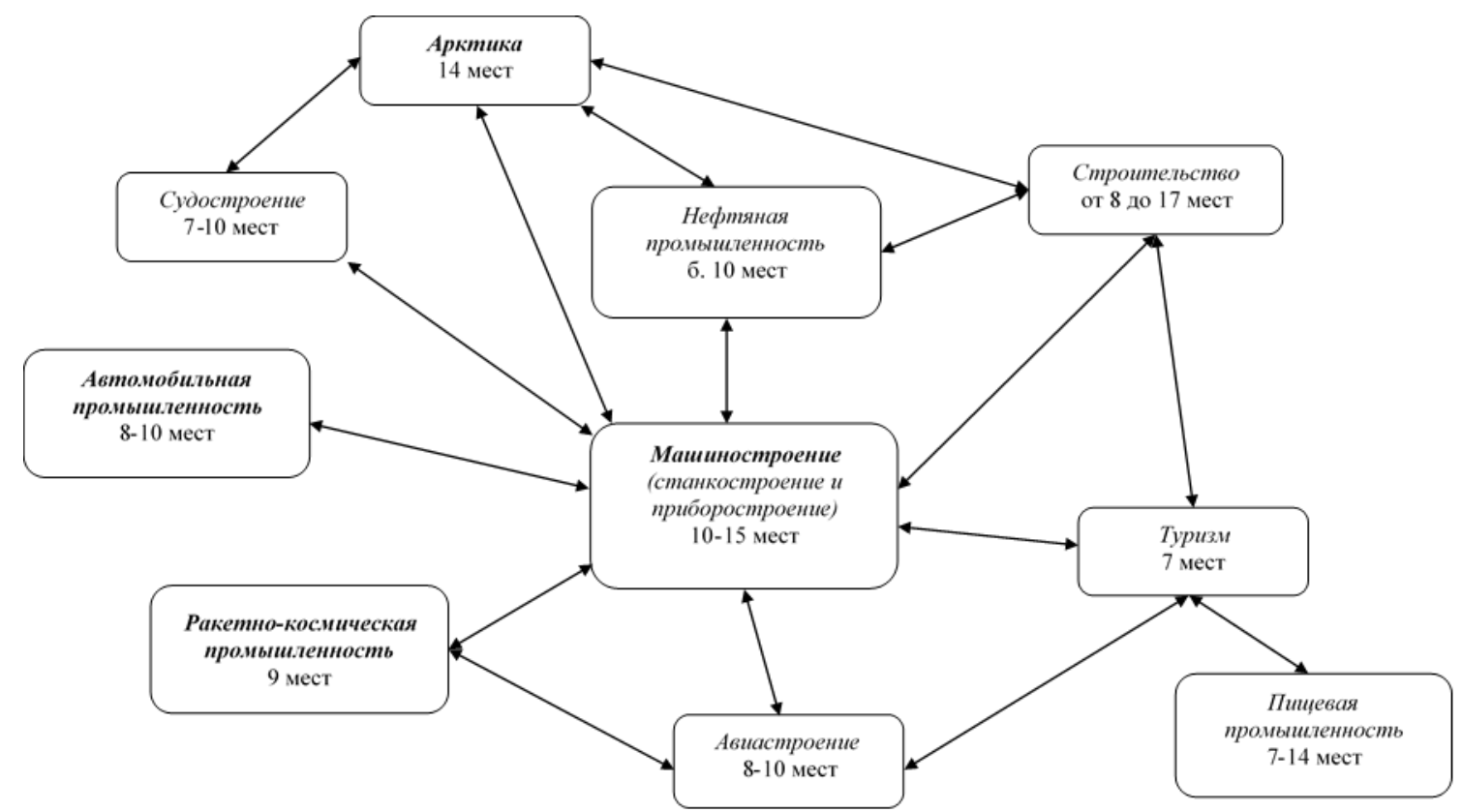

Рис. 2. Мультипликативные эффекты создания рабочих мест в ключевых отраслях российской экономики.

Источник: оставлено автором на основе [4,5,6,3,7,8,9,10].

Реализация данного подхода требует сосредоточения на трудоёмких отраслях с большим объёмом первоначальных капитальных вложений.

Рассмотрим конкретный пример. Для развития Арктики необходимо создание условий для нормального проживания за полярным кругом нескольких тысяч специалистов, что уже само по себе является непростой задачей. В соответствующих регионах Канады отсутствует постоянное население, т.к. в этой стране преимущественно прибегают к вахтовому методу 
работы в приарктических зонах. Можно с уверенностью сказать, что в деле построения городов в Заполярье Россия обладает несомненными конкурентными преимуществами и накопила значительный опыт.

В данном контексте Северный Морской Путь предстаёт важнейшей артерией, которая обеспечивает функционирование и прогресс Заполярья. Реконструкция системы Северного морского коридора предполагает модернизацию узлов по всей системе железнодорожного, морского и речного сообщения данных территорий, аэропортов и аэродромов, развитие сети внутри региональных автодорог и улучшение их характеристик. Также формирование на новой технологической базе общих инфраструктурных систем, упорядочение и расширение энергоснабжения во всех сферах деятельности и перевод потребителей энергии на централизованные виды энергообеспечения. Наиболее важным является модернизация флота - спуск на воду новых атомных ледоколов, нефтеналивных судов и лихтеровозов ледового класса, создание новых морских платформ и т.п. [11].

Значительный рост объёмов коммерческих транзитных грузов по маршруту Северного морского пути даст возможность резко снизить страховые сборы за проход судов по трассе, интенсифицировать её транзитное использование и перейти с оплаты тоннажа за ледокольную проводку судов на обычную для многих морских каналов плату за пользование. Также в Арктическом регионе России имеется множество разведанных источников минеральных ресурсов, включая месторождения газа в Печорском и Карском морях, нефти Ванкорского и Тугульского нефтяных месторождений на Енисее, никеля на полуострове Таймыр, апатитов, меди и алюминия на Кольском полуострове, золота и олова на Чукотском полуострове.

Из вышеизложенного следует, что наиболее актуальными для России будут направления научно-технического и инновационного развития, прямо или опосредованно связанные с освоением Арктики. К таким направлениям можно отнести:

- технологии добычи трудно извлекаемых нефти и газа глубокого (шельфового) залегания. Как известно, у России нет собственных готовых технологий в данной сфере. Ввиду санкций, наложенных на Россию странами Запада, и прямого запрета передачи упомянутых технологий нашей стране, возможно сотрудничество со странами, имеющими развитый промышленный и научно-технический потенциал, но имеющими серьезные геополитические разногласия со странами Запада, и хорошие отношения с РФ. Например, на эту роль могут претендовать страны БРИКС. 
- разработка новых технологий постройки судов ледового класса, в т.ч. позволяющих снизить стоимость данного процесса (за счет модульности). Целесообразно в сотрудничестве с Китаем, возможно, с меньшей вероятностью, с Южной Кореей.

- разработка конструкции модульных морских / речных портов и аэропортов, в т.ч. для средств малой авиации. Возможно в сотрудничестве с Китаем, Индией, Бразилией.

Таким образом, определение приоритетов инновационного развития РФ в тесной связи с реализацией крупных инвестиционных проектов по освоению Арктики, Северного Морского Пути способно создать масштабные, значимые для экономики России мультипликативные межотраслевые эффекты.

Вывод. Путем проведения расчетов по коэффициенту связанности научно-технического сотрудничества, нами были определены наиболее перспективные направления расширения международных научно-технических связей РФ. Так, выявлено, что необходимо развивать сотрудничество со странами ЕС: Францией, Испанией, Германией, Италией по таким научным направлениям: энергия и окружающая среда, микро-, нано- и оптические технологии, авиационная и космическая техника, био- и пищевые технологии.

В работе были проанализированы межотраслевые мультипликаторы в России. На основе нашего анализа мнений экспертов, наибольший мультипликативный эффект был выявлен в машиностроении, развитии Арктики, автомобильной, авиационной и ракетно-космической отраслях РФ. При корректировке приоритетов научно-технологического развития РФ следует их ранжировать по величине межотраслевых мультипликаторов в указанных отраслях.

Исследование подтвердило тезис о необходимости расширения международного научно-технического сотрудничества РФ. Обосновано, что, несмотря на негативную геополитическую обстановку (санкции), России необходимо продолжать и расширять научно-техническое сотрудничество со странами Евросоюза, а по тем направлениям, где это не представляется возможным в силу отказа от сотрудничества со стороны партнеров из ЕС, привлекать к кооперации страны БРИКС. Например, это касается разработки технологий добычи трудно извлекаемых нефти и газа глубокого (шельфового) залегания, на которые через санкции введен прямой запрет на передачу России. Также такой подход применим к совершенствованию технологий постройки судов ледового класса. 
Гармоничное сочетание вышеуказанных рекомендаций для корректировки приоритетов научно-технологического и инновационного развития России позволит преодолеть отмеченные во введении недостатки существующих приоритетов, зафиксированных в нормативно-правовых документах РФ.

\section{Список литературы}

1. Рифкин Дж. Третья промышленная революция. Как горизонтальные взаимодействия меняют энергетику, экономику и мир в целом. / Пер. с англ. М.: Альпина, 2014. -410 с.

2. Шваб, К. Четвёртая промышленная революция. / К. Шваб - М.: Эксмо, 2016. - 208 с.

3. Кобылкин, Д. Одно рабочее место в Арктике создает 14 рабочих мест в России / Д. Кобылкин // Информационное агентство «Рамблер». Режим доступа: https://finance.rambler.ru/economics/31862853/?utm_content=rfinance\&utm_mediu $\mathrm{m}=$ read_more\&utm_source=copylink (дата обращения: 23.03.2018).

4. Баверман, А. Одно рабочее место в строительстве создает 17 рабочих мест в других отраслях / А., Баверман // Сайт мониторинга рынка недвижимости «Где этот дом?». - Режим доступа: https://www.gdeetotdom.ru/news/1951733-2013-06-24-odno-rabochee-mesto-vstroitelstve-sozdaet-rabochih-mest-v-drugih/ (дата обращения: 06.04.2020);

5. Воронцов, И. Цементная промышленность: надежда на дороги / И. Воронцов // Информационное агентство «Минпром». - Режим доступа: https://www.minprom.ua/articles/253558.html (дата обращения: 03.03.2020).

6. Иванов, И. А. Микроэлектроника создает экосистему / И. А. Иванов // Новости цифровой трансформации, телекоммуникаций, вещания и ИТ «Comnews». - Режим доступа: https://www.comnews.ru/node/53898 (дата обращения: 03.04.2018);

7. Когогина, А. Депутат рассказала о повестке выездного заседания Комитета Госдумы по экономической политике / А. Когогин // Татар-информ. Режим доступа: https://www.tatar-inform.ru/news/2017/05/29/555232/ (дата обращения: 03.04.2018).

8. Мурадова 3.Р. Анализ развития строительной отрасли в Российской Федерации и Северо-Кавказском федеральном округе в 2013-2015 гг. / 
3. Р. Мурадова // Международная научная конференция «Общество, экономика и право-2016». - М., 2016. - 1 сессия. - С. 23-34.

9. Решетникова, Е. Стратегия вместо политики / Е. Решетникова // Российская Бизнес-газета - Промышленное обозрение. - М., 2011. - № 40(822). - C. 48-59;

10. Сафонов, О. Одно рабочее место в сфере туризма создает до семи рабочих мест в смежных отраслях / О. Сафонов // Агентство Бизнес Новостей. Режим доступа: https://abnews.ru/2016/01/20/safonov-odno-rabochee-mesto-vsfere-turizma-sozdaet-do-semi-rabochix-mest-v-smezhnyx-otraslyax/_ (дата обращения: 05.04.2020).

11. Евдокимов Ю. А. Северный морской путь: проблемы, возможности, перспективы возрождения / Ю. А. Евдокимов, Ю. М. Бацких, А. В. Истомин // Экономическая наука современной России. - 2000.— № 2.— С. 101.

() И.И. Приходько, 2021 